\title{
Nephro-protective effects of curcumin, rosemary and propolis against gentamicin induced toxicity in guinea pigs: Morphological and biochemical study
}

\author{
Azab El Saied Azab ${ }^{1}$, Fathy Ahmed Fetouh ${ }^{2}$, Mohamed Omer Albasha ${ }^{1}$ \\ ${ }^{1}$ Department of Zoology, Alegelat Faculty of Science, Zawia University, Libya \\ ${ }^{2}$ Department of Anatomy, Faculty of Medicine, Zagazig University, Egypt
}

Email address:

Fghait@yahoo.com (F. A. Fetouh)

\section{To cite this article:}

Azab El Saied Azab, Fathy Ahmed Fetouh, Mohamed Omer Albasha. Nephro-Protective Effects of Curcumin, Rosemary and Propolis against Gentamicin Induced Toxicity in Guinea Pigs: Morphological and Biochemical Study. American Journal of Clinical and Experimental Medicine. Vol. 2, No. 2, 2014, pp. 28-35. doi: 10.11648/j.ajcem.20140202.14

\begin{abstract}
The kidney is a common target for toxic xenobiotics due to its capacity to extract and concentrate toxic substances by highly specialized cells and also, due to its large blood flow. Objective: The present work aimed to evaluate the effectiveness of different natural materials (curcumin, rosemary and propolis) against the histological and also biochemical alterations of gentamicin induced nephrotoxicity in guinea pigs. Materials and methods: 48 guinea pigs were used for this study and divided into 8 groups. The first 4 groups were control groups, the 5 th group was the experimental and administered gentamicin at a dose of $100 \mathrm{mg} / \mathrm{kg}$ body wt for 10 days, and in the 6th, 7th , and 8th groups, gentamicin was co-administered with curcumin, rosemary, and propolis at the doses of $200 \mathrm{mg}, 220 \mathrm{mg}$, and $100 \mathrm{mg} / \mathrm{kg}$ body wt respectively. The animals were sacrificed and the kidneys were dissected and specimens were obtained. The specimens were processed for light microscopic examinations. Blood samples were obtained for assessment of urea, creatinine and uric acid levels. Results: In gentamicin treated animals, there were structural changes. The proximal convoluted tubules showed degenerated epithelial lining with disruption of their brush borders and presence of epithelial debris inside their lumens. The renal corpuscle appeared with degeneration of the glomerulus and disrupted Bowman's capsule. The afferent arteriole showed thickening in its wall and degeneration of endothelial lining with extensive perivascular infiltration of inflammatory cells. Massive interstitial hemorrhage was seen. Also, the serum urea, creatinine, and uric acid were elevated. Co-administration of curcumin, rosemary, and propolis significantly improved the structural changes in the kidney and the blood urea, creatinine and uric acid were significantly declined. Conclusion: It can be concluded that, the gentamicin has adverse effects on the kidney. Different natural materials as curcumin, rosemary, and propolis were able to protect the kidney against these effects. So, the patients should be advised to take one of these materials while they are treated by gentamicin.
\end{abstract}

Keywords: Nephrotoxicity, Histology, Biochemical, Gentamicin, Curcumin, Rosemary, Propolis

\section{Introduction}

The kidney is a common target for toxic xenobiotics due to its capacity to extract and concentrate toxic substances by highly specialized cells and also, due to its large blood flow (about 21\% of cardiac output) [1,2]. Aminoglycoside antibiotics have long been used in antibacterial therapy. Gentamicin is an aminoglycoside antibiotic derived from micomonospora purpurea. It is effective against most of the life threatening Gram negative bacterial infection [3]. The gentamicin still constitutes the only effective therapeutic alternative against microorganisms, pseudomonas, proteus and serratia that are insensitive to other antibiotics [4]. It has been estimated, that up to $30 \%$ of patients treated with aminoglycosides for more than 7 days show some signs of nephrotoxicity $[5,6]$. In addition, gentamicin nephrotoxicity accounts for $10-15 \%$ of all cases of acute renal failure [7] and nearly $10-25 \%$ of human patients treated with gentamicin exhibit increased blood urea nitrogen concentration subsequent to a reduction of glomerular filtration rate $[3,8]$. This gentamicin induced renal injury is related to increase the generation of superoxide anions, hydroxyl radicals, hydrogen peroxide and reactive nitrogen species in the kidney $[4,9,10]$. Several natural products have been used to protect the toxicities induced by drugs. Herbs 
are generally considered safe and proved to be effective against various human ailments and their medicinal uses have been gradually increasing in developed countries [11]. Natural antioxidants strengthen the endogenous antioxidants defenses and restore the optimal balance by neutralizing reactive species [12]. Curcumin as one of the naturally occurring dietary substances has been used since ancient times for promoting human health [13]. Curcumin is a major yellow pigments in rhizomes of curcuma longa linn which is used widely as a spice and coloring agent in several foods [13-15]. It represents a class of anti-inflammatory and anti-oxidant reported to be a potent inhibitor of ROS formation $[14,16]$. Rosemary (Rosmarinus Officinalis ) is a herb commonly used as spice and flavoring agent in food processing. It is composed of dried leaves and flowers constitutes a particularly interesting source of biologically active phytochemicals as it contains a variety of phenolic compounds including carnosol, carnosic acid, rosmanol, 7-methyl-epirosemanol, isorosmanol, rosmadial and caffeic acid $[12,17]$. Rosemary has anti-inflammatory action [18]. Propolis is resinous natural product collected from cracks in the bark of trees and leaf buds which are enriched with the salivary enzymes of honey bees. It has gained popularity and was used extensively in healthy drinks and foods to improve well-being and prevent diseases such as inflammation, heart diseases, diabetes and even cancer [19-21]. It has more than 180 compounds including flavonoids, phenolic acids and its esters [20,21]. Melatonin and caffeic acid phenethyl ester (CAPE) are compounds of hony bee propolis, that were recently found to be potent free radical scavengers and antioxidants [22]. Propolis possesses several biological properties such as anti-inflammatory, antioxidant, anticancer, antibiotic and antifungal activities [19-21]. Most of the previous literatures studied the protective effects of one antioxidant substance on the biochemical nephrotoxicity of the gentamicin but not much of them which studied the morphological alterations. Also, to our knowledge, the evidence reporting the protective effect of rosemary and propolis against gentamicin induced nephrotoxicity are very few.

\section{Aim of the Work}

The present work aimed to evaluate effectiveness of different natural materials (curcumin, rosemary and propolis) against the histological and biochemical alterations of gentamicin induced nephrotoxicity in guinea pigs .

\section{Materials and Methods}

\subsection{Chemicals}

Gentamicin and curcumin were purchased from Sigma Chemical Co. (St. Louis, Mo, USA). Rosemary was purchased as dried rosemary leaves from a herbal store in Zagazig city, Egypt. Aqueous rosemary extract was prepared according to the method of Amin and Hamza [23]. Briefly, ten gm of dried plants was slowly boiled in $100 \mathrm{ml}$ of distilled water and heated for 30 minutes. The extracts were then filtered and directly administered orally by gavage to the animals. The given dose was $220 \mathrm{mg} / \mathrm{kg}$ b. wt. Crude propolis was obtained from hony bee colonies in the Faculty of Agriculture, Zagazig University, Egypt. Aqueous propolis extract was prepared according to the method of El-khayat et al. [24]. Briefly, propolis was kept dry and freezed (-40 $\square$ ) until used. Propolis samples were mixed with distilled water, heated gently and filtered through Whatman no: 1 filter paper. Propolois was freshly prepared and administered to animals orally by gavage at a dose of $100 \mathrm{mg} / \mathrm{kg} \mathrm{b}$. wt. Gentamicin was injected intraperitoneally at the dose of $100 \mathrm{mg} / \mathrm{kg} \mathrm{b}$. wt for ten successive days on the bases that the nephrotoxicity occurs with a wide range of gentamicin doses (20-180 mg $/ \mathrm{kg}$ b. wt, as found by Elfarra et al. [25], Kumar et al. [26], Ali et al. [27] and Cuzzocrea et al. [9]. The choice of the doses of curcumin, rosemary and propolis were based on the results of the previous studies, where the antioxidant effects of these agents were confirmed. Curcumin was given orally at a dose of $200 \mathrm{mg} / \mathrm{kg} \mathrm{b}$. wt by gavage [28,29]. Rosemary was given at a dose of $220 \mathrm{mg} / \mathrm{kg} \mathrm{b}$. wt orally by gavage $[30,31]$ and the propolis was given at a dose of $100 \mathrm{mg} / \mathrm{kg} \mathrm{b}$. wt orally by gavage [24].

\subsection{Animals}

48 adult male guinea pigs (Cavia porcellus) weighting 480-530 gm were used for this study. The animals were obtained from animal house unit in the Faculty of Veterinary Medicine, Zagazig University, Egypt. The animals were housed in a room under standard conditions of ventilation, temperature $\left(25 \pm 2{ }^{\circ} \mathrm{C}\right)$, humidity $(60-70 \%)$ and light/dark condition (12/12). The animals were provided with tape water ad libitum and fed with the standard commercial chow. The animal procedures were performed in accordance with Guide Lines for Ethical Conduct in the Care and Use of Animals.

\subsection{Experimental Design}

After one week of acclimation, the animals were randomized and divided into 8 groups (6 guinea pigs for each) as follow:

Group 1 (control group): The animals received intraperitoneal injection of saline $(0.5 \mathrm{ml} /$ day for 10 days $)$.

Group 2 (curcumin only): The animals received curcumin (200 mg/kg b. wt /day) orally by gavage for 10 days.

Group 3 (rosemary only): The animals received rosemary $(220 \mathrm{mg} / \mathrm{kg} \mathrm{b}$. wt /day) orally by gavage for 10 days.

Group 4 (propolis only): The animals received propolis $(100 \mathrm{mg} / \mathrm{kg} \mathrm{b}$. wt /day) orally by gavage for 10 days.

Group 5 (gentamicin treated group): The animals received intraperitoneal injection of gentamicin only $(100 \mathrm{mg} / \mathrm{kg} \mathrm{b}$. wt /day) for 10 days.

Group 6 (gentamicin/curcumin co-administered): The animals received intraperitoneal injection of gentamicin (100 mg/kg b. wt /day) concurrently with curcumin (200 
$\mathrm{mg} / \mathrm{kg} \mathrm{b}$. wt /day ) orally for 10 days.

Group 7 (gentamicin/rosemary co-administered): The animals received intraperitoneal injection of gentamicin $(100 \mathrm{mg} / \mathrm{kg} \mathrm{b}$. wt /day) concurrently with rosemary $(220$ $\mathrm{mg} / \mathrm{kg} \mathrm{b}$. wt /day) orally for 10 days.

Group 8 (gentamicin/propolis co-administered): The animals received intraperitoneal injection of gentamicin $(100 \mathrm{mg} / \mathrm{kg} \mathrm{b}$. wt /day) concurrently with propolis (100 $\mathrm{mg} / \mathrm{kg} \mathrm{b}$. wt /day) orally for 10 days.

At the end of the experimentation and 24 hours after the last dose, the animals were sacrificed by injecting ketamine (intraperitoneal) under general anesthesia, then rapidly dissected and subjected to the following examinations:

\subsubsection{Histological Examination}

The kidneys were exposed by mid line incision and then rapidly dissected from the surrounding structures. Kidney specimens were obtained and fixed in buffered $10 \%$ formaldehyde solution for 24 hours and processed for paraffin sections of 5 micron thickness. The sections were stained with Hematoxylin and Eosin and examined under binocular light microscope (Zeiss)[32].

\subsubsection{Biochemical Analysis}

Blood samples were drown by cardiac puncture and centrifuged at $3000 \mathrm{rpm}$ for 15 minutes to harvest the serum with which the renal function assessment were analyzed. The levels of urea, creatinine, and uric acid were assessed in the sera of control and experimental animals [33,34]. Statistical analysis

The values were presented as means $\pm \mathrm{SD}$ of different groups. Differences between the mean values were estimated using one way ANOVA. The results were considered statistically significant when $\mathrm{p}<0.05$.

\section{Results}

Histologically, by light microscopic examination, the kidney appeared with normal structures in normal control and positive control animals (curcumin, rosemary, and propolis administered). The glomerulus appeared normal with intact Bowman's capsule and Bowman's space. The proximal convoluted tubules appeared in cross and longitudinal sections with intact limiting basement membrane and their lumens showed intact brush borders. The distal convoluted tubules showed wide lumens with low cuboidal lining cells. An afferent arteriole appeared near the glomerulus (Fig. 1).

In gentamicin treated animals, the proximal convoluted tubules showed degenerated epithelial lining with disruption of their brush borders and presence of epithelial debris inside their lumens. The renal corpuscle appeared with degeneration of the glomerulus and disrupted Bowman's capsule. The afferent arteriole appeared near the glomerulus with thickening in its wall and degeneration of endothelial lining. Extensive perivascular infiltration of inflammatory cells and massive interstitial hemorrhage were seen (Fig. 2)

In animals co-administered with gentamicin and curcumin, most of the proximal convoluted tubules appeared with normal epithelial lining and regained their brush borders. Some tubules still have diminished brush borders. The glomerulus appeared normal with intact Bowman's capsule (Fig. 3).

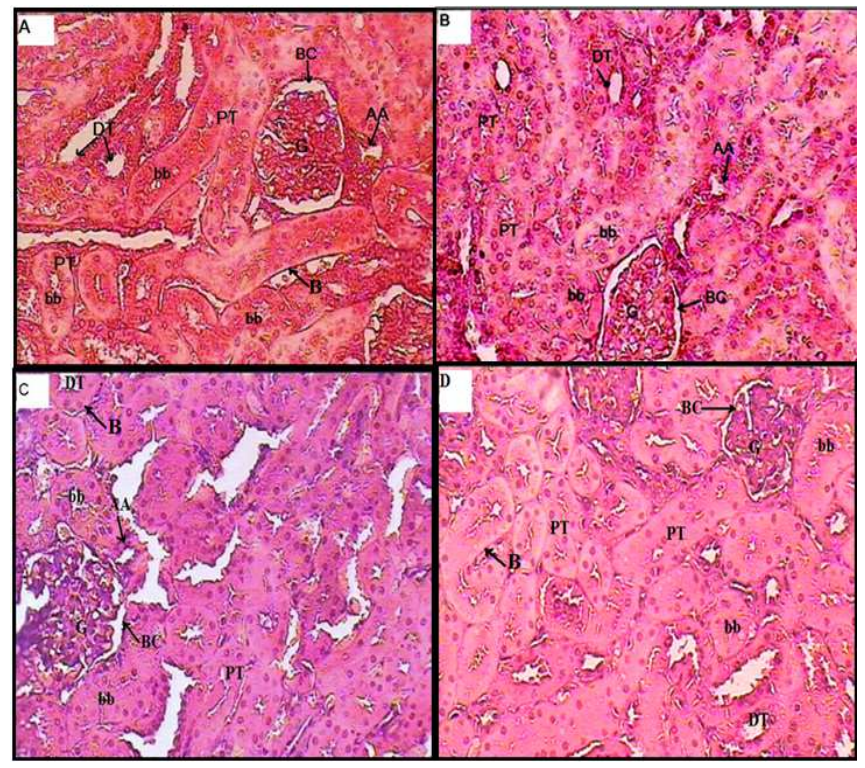

Fig 1. Light micrograph of sections in the kidney of control guinea pigs; A: negative control (administered saline), B: positive control (administered curcumin only), $C$ : positive control (administered rosemary only), D: positive control (administered propolis only). Glomerulus $(G)$, Bowman's capsule $(B C)$, proximal convoluted tubules $(P T)$, basement membrane $(B)$ brush border (bb). distal convoluted tubules (DT). afferent arteriole (AA) (Haematoxylin \&Eosin $\times 400$ )

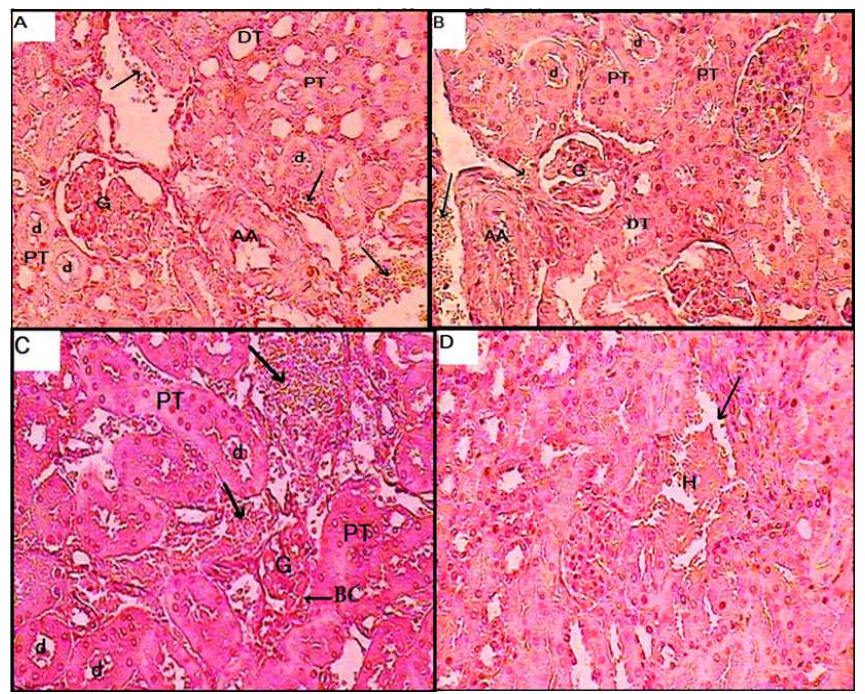

Fig 2. Light micrograph of sections in the kidney of gentamicin treated guinea pigs. A\&B: The proximal convoluted tubules (PT) show degenerated epithelial lining with epithelial debris (d) inside the lumens. The distal convoluted tubules (DT) appear normal. The glomerulus $(G)$ is degenerated. The afferent arteriole (AA) shows thickening in the wall and degeneration of endothelial lining with perivascular infiltration of inflammatory cells (arrows). C: Shows degenerated glomerulus with disrupted Bowman's capsule (BC). Epithelial debris (d) appears inside lumens of the proximal convoluted tubules (PT). Extensive inflammatory cell infiltrations appear in the interstitial tissues (arrows). D: Congested intertubular capillary (arrow) is seen with massive hemorrhage $(H)$. (Haematoxylin \& Eosin $\times 400)$ 
In animals co-administered with gentamicin and rosemary, the proximal convoluted tubules appeared with normal epithelial lining and regained their brush borders. The glomerulus appeared more or less normal with intact Bowman's capsule (Fig. 4).

In animals co-administered with gentamicin and propolis, most of the proximal convoluted tubules appeared with normal epithelial lining with their brush borders, but some tubules appeared regenerating with disrupted brush borders. The glomerulus appeared normal with intact Bowman's capsule (Fig. 5)

Biochemically, the levels of serum urea, creatinine and uric acid increased in the gentamicin treated group in comparison with control group with significant differences. The values decreased in the co-administered gentamicin and curcumin, gentamicin and rosemary and gentamicin and propolis with significant differences (Table 1 and Figs. $6,7,8)$.

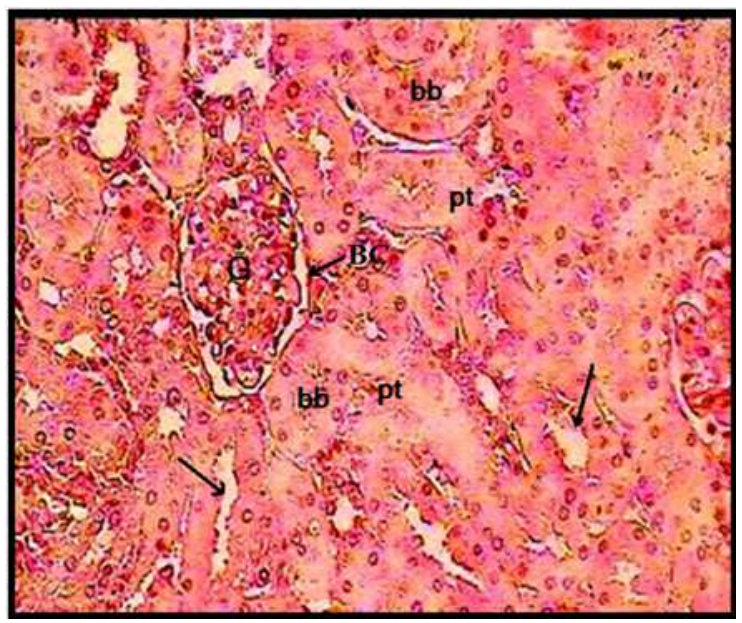

Fig 3. Light micrograph of a section in the kidney of gentamicin treated guinea pigs co-administered curcumin. Most of the proximal convoluted tubules (PT) appear with normal epithelial lining and regained their brush borders (bb). Some tubules still have diminished brush borders (arrows). The glomerulus $(G)$ appears normal with intact Bowman's capsule (BC). (Haematoxylin \&Eosin $\times 400$ )

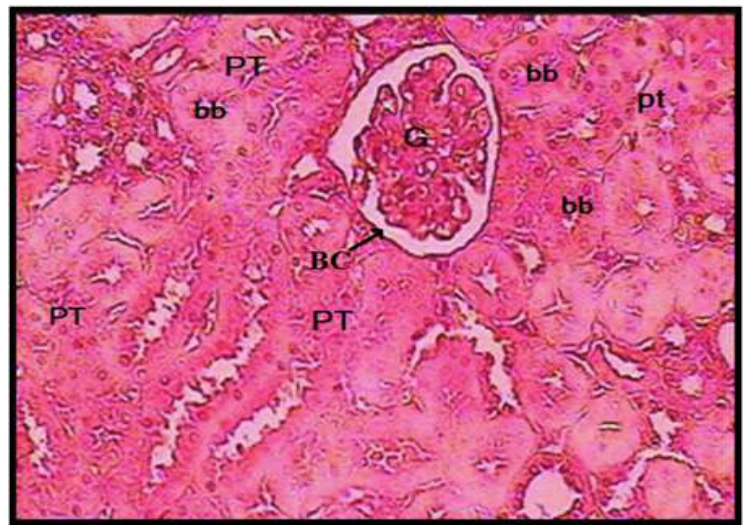

Fig 4. Light micrograph of a section in the kidney of gentamicin treated guinea pigs co-administered rosemary. The proximal convoluted tubules (PT) appear with normal epithelial lining and regained their brush borders $(b b)$. The glomerulus (G) appears more or less normal with intact Bowman's capsule (BC). (Haematoxylin \&Eosin $\times 400$ )

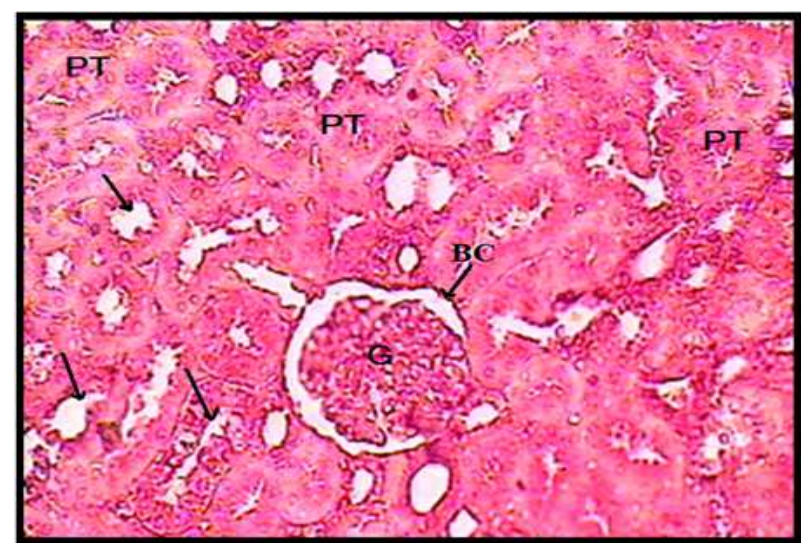

Fig 5. Light micrograph of a section in the kidney of gentamicin treated guinea pigs co-administered propolis. Most of the proximal convoluted tubules (PT) appear with normal epithelial lining with their brush borders, but some tubules appear regenerating with disrupted brush borders (arrows). The glomerulus $(G)$ appears normal with intact Bowman's capsule $(B C)$. (Haematoxylin \&Eosin $\times 400$ )

Table 1. Effect of curcumin, propolis and rosemary on serum urea, creatinine, and uric acid in the kidney of gentamicin treated male guinea pigs (Cavia porcellus) in different groups.

\begin{tabular}{cccc}
\hline Group & $\begin{array}{c}\text { Urea }(\mathbf{m g} / \mathbf{d l}) \\
\text { Mean } \pm \text { SD }\end{array}$ & $\begin{array}{c}\text { Creatinene } \\
(\mathbf{m g} / \mathbf{d l}) \\
\text { Mean } \pm \text { SD }\end{array}$ & $\begin{array}{c}\text { Uric acid(mg/dl) } \\
\text { Mean } \pm \text { SD }\end{array}$ \\
\hline Control & $21.2 \pm 2.9$ & $0.525 \pm 0.019$ & $1.317 \pm 0.248$ \\
Curcumin & $16.3 \pm 1.03$ & $0.503 \pm 0.014$ & $1.883 \pm 0.117$ \\
Propolis & $16.2 \pm 1.17$ & $0.302 \pm 0.016$ & $1.45 \pm 0.105$ \\
Rosemary & $15.7 \pm 0.75$ & $0.31 \pm 0.013$ & $1.183 \pm 0.075$ \\
Gentamicin & $54.2 \pm 1.2^{*}$ & $1.358 \pm 0.308^{*}$ & $3.283 \pm 0.279^{*}$ \\
Gentamicin + & $29.8 \pm 3.2^{* *}$ & $0.618 \pm 0.025^{* *}$ & $2.117 \pm 0.116^{* *}$ \\
Curcumin & & & \\
Gentamicin + & $27.8 \pm 1.2^{* *}$ & $0.36 \pm 0.014^{* *}$ & $1.983 \pm 0.014^{* *}$ \\
Propolis & & & \\
Gentamicin+ & $24.5 \pm 1.9^{* *}$ & $0.448 \pm 0.036^{* *}$ & $1.85 \pm 0.187^{* *}$ \\
\hline Rosemary & &
\end{tabular}

${ }^{*} \mathrm{p}<0.05$ when compared to control group, ${ }^{* *} \mathrm{p}<0.05$ when compared to gentamicin treated group, all data are mean of 6 animals

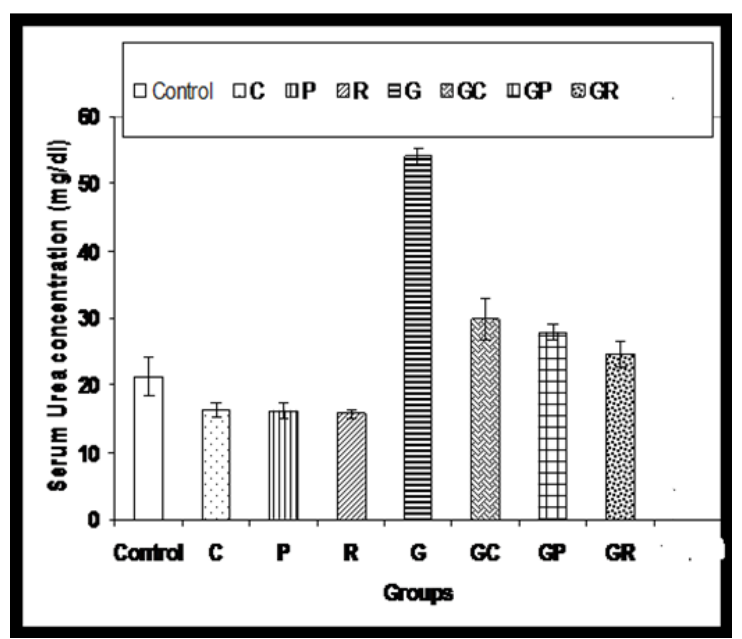

Fig 6. The serum urea level in different animals groups. The level is the highest in gentamicin treated group $(G)$ in comparison with control groups; normal control, curcumin treated (c), propolis treated ( $p)$, and rosemary treated $(R)$. The level shows declining in co-administered gentamicin and curcumin $(G C)$, gentamicin and propolis $(G P)$ and gentamicin and rosemary $(G R)$. 


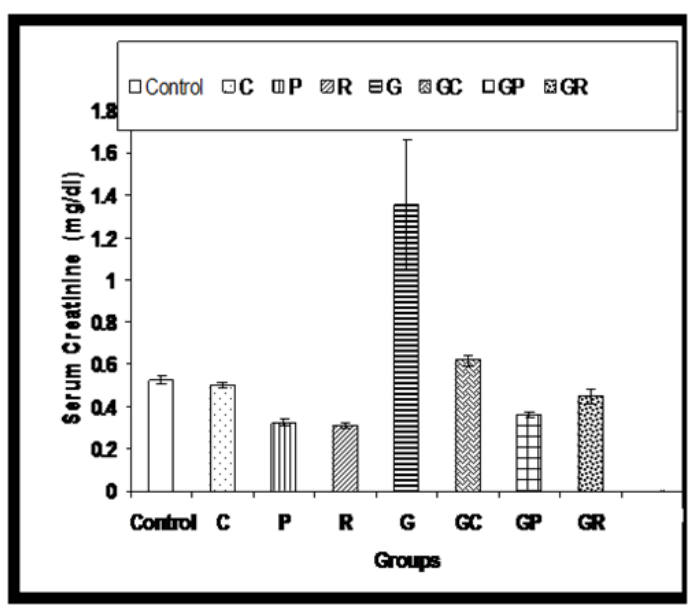

Fig 7. The serum creatinine level in different animals groups. The level is the highest in gentamicin treated group $(G)$ in comparison with control groups; normal control, curcumin treated (C), propolis treated (p), and rosemary treated $(R)$. The level shows declining in co-administered gentamicin and curcumin (GC), gentamicin and propolis (GP) and gentamicin and rosemary $(G R)$.

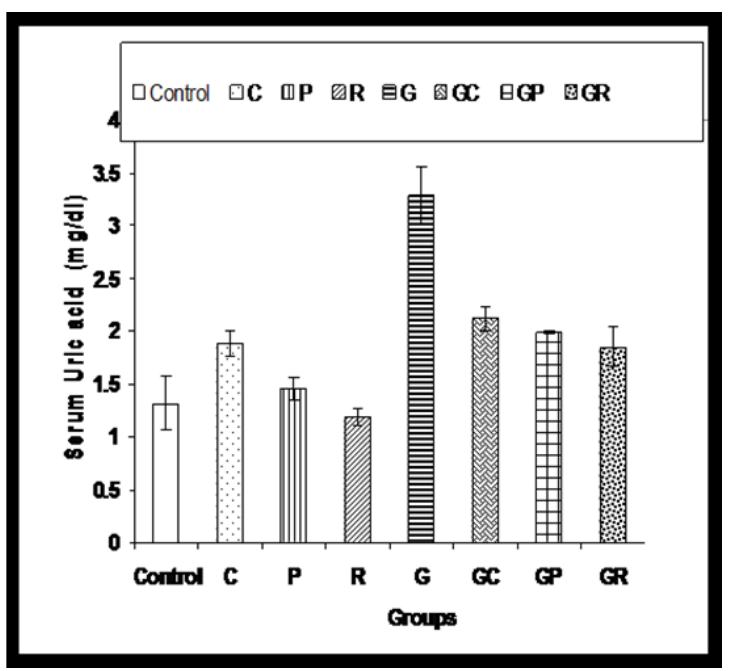

Fig 8. The serum uric acid level in different animals groups. The level is the highest in gentamicin treated group $(G)$ in comparison with control groups; normal control, curcumin treated $(C)$, propolis treated $(p)$, and rosemary treated $(R)$. The level shows declining in co-administered gentamicin and curcumin (GC), gentamicin and propolis (GP) and gentamicin and rosemary (GR)

\section{Discussion}

In the present study, the gentamicin had adverse effects on the kidney structure mainly on the proximal convoluted tubules, renal corpuscle, vessels, and interstitial tissues. The proximal tubules showed degeneration of the epithelial lining with disruption of their brush borders and presence of epithelial debris in the lumen. The renal corpuscles showed degeneration in the glomerulus and disrupted Bowman's capsule. The vessels showed thickening of the wall and degeneration of the endothelial lining. The interstitial tissues showed perivascular infiltration of inflammatory cells and interstitial massive hemorrhage. This is in agreement with many authors who reported the toxicity of gentamicin on the kidney. Padmini and Kumar [35] observed epithelial cell degeneration and granular deposits in tubular lumens with evidence of tubular epithelial cell desquamation and lymphocytic infiltration around the proximal convoluted tubules. Manikandan et al. [36] observed damaged glomerular structure, tubular necrosis, thickening of capillary walls and atrophy of glomerular tuft. Lakshmi and Sudhakar [37] observed epithelial desquamation in proximal tubules, tubular necrosis, epithelial oedema and glomerular hypertrophy. Souza et al. [38] observed apoptosis, intracellular oedema, basement membrane interruption, glomerular narrowing of the Bowman's capsule and acute tubular necrosis. Ali and Bashir [39] and Elfarra et al. [25] observed severe and complete necrosis of the proximal tubules throughout the cortex. Nale et al. [40] observed degenerative changes in glomeruli with hypercellularity and also atrophy of the glomeruli. Few areas showed interstitial hemorrhage and infiltration of mononuclear cells. Kang et al. [41] observed diffuse cellular necrosis in the proximal tubules. In addition, the lumens of the tubules were filled with degenerated and desquamated cells, massive hyaline cast and severe inflammatory cell infiltrations. The finding of the present study supported by the previous literatures indicated that the gentamicin has affinity to the proximal tubules without distal tubules affection. On the other hand, Nale et al. [40] observed tubular changes like diffuse tubular swelling and loss of tubular epithelium which were prominent at many foci in both proximal and distal tubules. Lakshmi et al. [42] observed epithelial desquamation, accumulation of inflammatory cells and necrosis of the kidney cells. Some literatures recorded slight effects on the distal tubules. Ullah et al. [43] observed loss of the cellular pattern with the presence of necrosis mostly in the proximal tubule in rabbit kidney treated with gentamicin. Alarifi et al. [44] found that the tubular damage is more prominent in proximal tubules than distal tubules. This predominant toxicity in the proximal tubules is caused by taking up the aminoglycosides into the epithelial cells of the renal proximal tubules and stay for a long time which lead to nephrotoxicity [45]. Also, the accumulation of gentamicin in proximal renal tubules leads to brush border network damage [46]. The proximal convoluted tubules are the primary sites for re-absorption and active transport. This leads to a higher concentration of gentamicin in the epithelial lining of these tubules and suggests that the gentamicin toxicity is related to its accumulation in the proximal tubules $[44,47]$. Also, the tubular necrosis were observed without any changes in glomerular structure [9].

Many authors explained the mechanisms of gentamicin induced nephrotoxicity. The gentamicin administration is suggested to increase renal cortical lipid peroxidation, nitric oxide generation and mitochondria hydrogen peroxide production and all these molecules induce cellular injury and necrosis by several mechanisms, including peroxidation, protein denaturation and DNA damage $[10,48]$. Also, the gentamicin induces renal tubular damage via energy depletion in renal tubular cells beside inducing of oxidative 
stress [49]. In addition, It induces cellular injury and necrosis by reducing the efficiency of antioxidant enzymes in the kidney such as superoxide dismutase, catalase, glutathione peroxidase and glutathione [50]. Gentamicin binds to the phospholipids of the cell membrane of the renal tubules and enters inside the cells, then it binds to subcellular organelles, alters the mitochondrial respiration and small amount may be taken up by lysosomes [51]. Moreover both, lysosomes and mitochondria have been shown to send death signals through the activation of specific stress sensors. Also, lysosomes membrane rupture and release of acid hydrolases contribute to apoptosis and necrosis of proximal tubular cells [52]. In the present study, co-administration of curcumin in animals treated by gentamicin ameliorated the structural changes of the kidney. This is in agreement with Manikandan et al. [36] who found that curcumin affords curative role against nephrotoxicity induced gentamicin exposure and reduces gentamicin induced renal injury and this is supported by Biswas et al. [53] who found that curcumin has anti-inflammatory and antioxidant properties with a potent ability to inhibit reactive oxygen species formation.

In the present study, co-administration of rosemary to animals treated with gentamicin regained the structural changes to normal. This is in agreement with Tavafi and Ahmadvand [54] who found that co-treatment of gentamicin and rosemarinic acid significantly decreased the tubular necrosis. Also, the rosemary aqueous extract alleviates the nephrotoxicity induced by CCL4 in albino rats [31]. The protective effect of rosemary can be explained that rosemary extract has a high scavenging capacity of different types of reactive oxygen and nitrogen species, mostly free radicals, as thought to be one of the main mechanisms of the antioxidant action exhibited by phenolic phytochemicals [55]. Also, the rosemary aqueous extract alleviates the toxicity induced by lead on the kidney through stimulation of endogenous antioxidant defense system [56]. In addition, rosemary has anti inflammatory action [18].

In the present study, co-administration of propolis to gentamicin treated animals improves the structural changes induced by gentamicin. This is in agreement with Osman and Tantaway [57] who observed that oral administration of propolis extract to rabbit significantly protected against histopathological alterations induced by gentamicin. Atta et al. [58] found that propolis ameliorated the renal alterations induced by gentamicin administration as indicated by maintenance of the activity of antioxidant enzymes. Park and Kahng [59] found that propolis extract had profound anti-inflammatory effects on both chronic and acute inflammations.

Functionally, the levels of serum urea, creatinine, and uric acid increased in gentamicin treated group in comparison with control groups. This is in agreement with Moghaddam et al. [60], Soliman et al. [61] and Sivachandran and Hariharan [62] who found that the gentamicin nephrotoxicity is functionally characterized by increase in serum creatinine, urea, and blood urea nitrogen.
Co-administration of curcumin, rosemary, and propolis ameliorated the renal function. This is in agreement with Salem et al. [63] who found that co-administration of propolis with gentamicin decreased the rise in blood urea and serum creatinine. This effect is probably due to the antioxidant protective effect of propolis which could have accumulated in the cells of the proximal convoluted tubules of the kidney where propolis was reported to be collected and secreted [64]. Also, co-treatment of gentamicin and rosemarinic acid significantly decreased serum creatinine and urea [54].

\section{Conclusion}

It can be concluded that, the gentamicin has adverse effects on the kidney. Different natural materials as curcumin, rosemary, and propolis were able to protect against these effects. So, the patients should be advised to take one of these material while they are treated by gentamicin.

\section{References}

[1] Salgado CM, Hernades FL and Novoa JM: Glandular nephrotoxicity of aminonucleosides. Toxicol App Pharmacol 2007;223: 86-98

[2] Choi JJ, Moffett BS, McDade and Palazzo DL: Altered gentamicin serum concentration in obese pediatric patients. Pediat Infect Dis J 2011;30: 347-349

[3] Kaloyanides GJ: Metabolic interactions between drugs and renal tubulo-interstitial cells: role in nephrotoxicity. Kidney Int 1991; 39: 531-540

[4] Balakumar P, Chakkarwar VA, Kumar V, Jain A, Reddy J and Singh M: Experimental models for nephropathy. J Renin Angiotensin Aldosterone System 2008;9: 189-95

[5] Mattew TH: Drug-induced renal disease. Med J Aust 1992;156: 724-728

[6] Ali BH: Agents ameliorating or augmenting experimental gentamicin nephrotoxicity. Some recent research. Food Chem Toxicol 2003;41: 1447-1452

[7] Rincon J, Romero M, Viera N, Pedreanea A and Mosquera J: Increased oxidative stress and apoptosis in acute puromycin aminonucleoside nephrosis. Int J Exp Pathol 2004;85(1): $25-33$

[8] DeBroe ME, Giuliano RA and Verpooten GA: Aminoglycoside nephrotoxicity: mechanism and prevention. Adv Exp Med Biol 1989;252: 233-245

[9] Cuzzocrea S, Mazzon E, Dugo L Serraino I, Di Paola R, Britti D, De Sarro A, Pierpaoli S, Caputi A, Masini E, Salvemini D: A role for superoxide in gentamicin mediated nephropathy in rats. Eur J Pharmacol 2002; 450(1): 67-76

[10] Karahan I, Atessahin A, Yilmaz S, Ceribassi AO, Sakin F: Protective effect of lycopene on gentamicin-induced oxidative stress and nephrotoxicity in rats. Toxicol 2005;215: 192-204 
[11] Heeba GH, and Abd-Elghany MI: Effect of combined administration of ginger (Zingiber Officinale Roscoe) and atorvastatin on the liver of rats. Phytomedicine 2010;17: 1076-81

[12] Ho C, Ferrara T, Chen Q, Rosen R and Huang M: Phytochemicals in teas and rosemary and their cancer preventive properties in: food phytochemicals for cancer prevention. American Chemical Society, Washington, DC, 1994, pp.2-19

[13] Joe B, Vijaykumar M, Lokesh BR: Biological properties of curcumin-cellular and molecular mechanisms of action. Crit Rev Food Sci Nutr 2004;44: 97-111

[14] Venkatesan N, Punithavathi D, Arumugan V: Curcumin prevents adriamycin nephrotoxicity in rats. $\mathrm{Br} \mathrm{J}$ Pharmacol 2000;12: 231-234

[15] Tirkey N, Kaur G, Vij G and Chopra K: Curcumin a diferuloylmethane, attenuates cyclosporine induced renal dysfunction and oxidative stress in rat kidneys. J Biosc 2005; 22(2): $233-46$

[16] Ruby AJ, Kuttan G, Babu KD and Kuttan R: Anti-tumor and anti-oxidant activity of natural curcuminoids. Cancer Lett 2005;94: 79-83

[17] Aruoma O, Halliwell B, Aeschbach R, Loligers J: Antioxidant and pro-oxidant properties of active rosemary constituents: carnosol and carnosic acid. Xenobiotica 1992;22: $257-268$

[18] Altinier G, Sosa S, Aquino RP, Mencherini T, Della Loggia R, Tubaro A: Characterization of topical anti-inflammatory compounds in Rosmarinus Officinalis L. J Agric Food Chem 2007;55: 1718-1723

[19] Marquele FD, Di Mambro VM, Georgetti SR, Casagrande R, Valim YML and Fonseca MJV: Assessment of the antioxidant activities of Brazilian extracts of propolis alone and in topical pharmaceutical formulation. $\mathrm{J}$ Pharmacol Biomed Anal 2005;39: 455-462

[20] Li YJ, Lin JL, Yang CW and Yu CC: Acute renal failure induced by a Brazilian variety of propolis. Am J Kid Dis 2005;46(6): e125-9

[21] Gunduz C, Biray C, Kosova B, Yilmaz B, Eroglu Z, Sahin F, Omay SB and Cogulu O: Evaluation of Manisa propolis effect on leukemia cell line by telomerase activity. Leuk Res 2005;29(11): 1343-6

[22] Ozguner F, Bardak Y and Comlekci S: Protective effects of melatonin and caffeic acid phenethyl ester against retinal oxidative stress in long-term use of mobile phone. a comparative study. Mol Cell Biochem 2006;282(1-2): 83-88

[23] Amin A, and Hamza AA: Hepatoprotective effects of hibiscus, rosemarinus and salvia on azathioprine-induced toxicity in rats. Life Sciences 2005;77: 266-278

[24] El-Khayat Z, Ezzat AR, Arbid MS, Rasheed WI, Elias TR: Potential effects of bee honey and propolis against the toxicity of ochratoxin a in rats. Macedonian $\mathrm{J}$ Med Scie 2009;2(4): $1-8$

[25] Elfarra AA, Duescher RJ, Sausen PJ, O $\square$ Hara TM and Cooley AJ: Methimazole protection of rats against gentamicin-induced nephrotoxicity. Can J Physiol Pharmacol 1994;72: $1238-1244$
[26] Kumar KV, Naidu MUR, Shifow AA and Ratnakar KS: Probucol Protects against gentamicin-induced nephrotoxicity in rats. J Pharmacol 2000;32: 108-113

[27] Ali BH, Al-Qarawi AA, Mahmoud OM and Hashad M: Influence of spironolactone treatment on gentamicin -induced nephrotoxicity in rats. Basic Clin Pharmacol Toxicol 2004;95: 20-23

[28] Chuang SE, Chen AL, Lin JK and Kuo ML: Inhibition by curcumin of diethylnitrosamine-induced hepatic hyperplasia, inflammation, cellular gene protection and cell-cycle related protein in rats . Food Chem Toxicol 2000;38: 991-995

[29] Ali BH, Al-Wabel N, Mahmoud O, Mousa HM, Hashad M: Curcumin has a palliative action on gentamicin-induced nephrotoxicity in rats. Fundamental and clin pharmacol 2005;19: 473-477

[30] Dorman HJ, Peltoketo A, Hiltunen R and Tikkanen MJ: Characterization of the antioxidants properties of de-odourised aqueous extracts from selected lamiaceae herbs. Food Chemistry 2003;83: 255-262

[31] Sakr SA and Lamfon HA: Protective effect of rosemary (Rosmarinus Officinalis) leaves extracts on carbon tetrachloride-induced nephrotoxicity in albino rats. Life science journal 2012;9(1): 779-785

[32] Ross MH, Reith EJ and Romrell LJ: Histology: A Text Atlas (2nded.). Baltimore. Williams \&Wilkins, 1989, pp.51-84

[33] Spencer K: Analytical reviews in clinical biochemistry: the estimation of creatinine. Ann Clin Biochem 1986;23: 1-25

[34] Banday AA, Farooq N, Priyamvada S, Yusufi ANK and Khan F: Time dependent effect of carbohydrate metabolism, brush border membrane and oxidative stress in rat kidney tissue. Life Science 2008;82: 450-459

[35] Padmini MP and Kumar JV: A histological study on gentamicin indued nephrotoxicity in experimental albino rats. J Dent Med Sci 2012; 1(1): 14-17

[36] Manikanadan R, Beulaja M, Thiagarajan R, Priyadarsini A, Saravanan R and Arumugam M: Ameliorative effects of curcumin against renal injuries mediated by inducible nitric oxide synthase and nuclear factor kappa B during gentamicin-induced toxicity in wister rats. Eur J Pharm 2011;670: 578-585

[37] Lakshmi BVS and Sudhakar M: Protective effect of zingiber officinalis on gentamicin induced nephrotoxicity in rats. Int $\mathrm{J}$ Pharmacol 2010;6: 58-62

[38] Souza VB, Oliveira RFL, Ferreira AAA and Araujo-junior RF: Renal alteration by aminoglycosides. Arq Med 2008:22(45): 131-135

[39] Ali BH and Basher AA: Effect of fish oil treatment on gentamicin nephrotoxicity in rats. Ann Nutr Metab 1994;38: 336-339

[40] Nale LP, More PR, More BK, Ghumare BC, Shendre SD and Mote CS: Protective effect of carica papaya 1. seed extract in gentamicin induced hepatotoxicity and nephrotoxicity in rats. Int J Pharm Bio Sci 2012;3(3): 508-515

[41] Kang C, Lee H, Hah D, Heo JH, Kim CH, Kim E, and Kim JS Protective effects of houttuynia cordata thunb on gentamicin induced oxidative stress and nephrotoxicity in rats. Toxicol Res 2013;29(1): 61-67 
[42] Lakshmi BVS, Neelima N, Kasthuri N, Umarani V and Sudhakar M: Protective effect of bauhinia purpurea on gentamicin induced nephrotoxicity in rats. Indian J Pharma Sci 2009;71(5): 551-554

[43] Ullah N, Khan MA, Khan T and Ahmad W: Protective effect of gentamicin induced nephrotic damage in rabbit. Trop J Pharmaceut Res 2013;12(2): 215-219

[44] Alarifi S, Al-Doaiss A, Alkahtani S, Al-Farraj SA, Al-Eissa MS, Al-Dahmash B, Al-Yahya H And Mubarak M: Blood chemical changes and renal histological alternations induced by gentamicin in rats. Saudi J Biol Sci 2012;19: 103-110

[45] Nagai J, And Takano M: Molecular aspect of renal handling of aminoglycosides and strategies for preventing the nephrotoxicity. Drug metab pharmacokinet 2004;19(3): $159-70$

[46] Whiting PH, and Brown PAS: The relationship between enzymuria and kidney enzyme activities in experimental gentamicin nephrotoxicity. Renal Failure 1996;18(6): 899-909

[47] Noorani AA, Gupta KA, Bhadada $\mathrm{K}$ and Kale MK: Protective effect of methanolic leaf extract of caesalpinia bonduc on gentamicin-induced hepatotoxicity and nephrotoxicity in rats. IJPT 2011;10: 21-25

[48] Parlakpinar H, Tasdemir S, Polat A, Bay-Karabulut A, Vardi N, Ucar M And Acet A: Protective role of caffeic acid phenethyl ester (cape) on gentamicin-induced acute renal toxicity in rats. Toxicol 2005;207: 169-177

[49] Tavafi M: Protection of renal tubular against gentamicin induced nephrotoxicity. J Ren Inj Prev 2013;2(1):5-6 doi:10.12861/jrip.2013.03

[50] Balakumar P, Rohilla $A$ and Thangathirupathi A: Gentamicin-induced nephrotoxicity: Do we have promising therapeutic approach to blunt it?. Pharmacol Res 2010; 62:179-186

[51] Erdem A, Gundogan NU, Usubutun A, Kilinc K, Erdem SR, Kara A and Bozkurt A: The protective effect of taurine against gentamicin-induced acute tubular necrosis in rats. Nephrol Dial Transplant 2000;15: 1175-1182

[52] Servais H, Van Dersmissen P, Thirion G, Vander Essen G, Van Bambeke F, Tulkens PM and Mingeot-leclercq MP: Gentamicin-induced apoptosis in LLC-PKI cells: involvements of lysosomes and mitochondria. Toxicol Appl Pharmcol 2005;206(3): 321-333

[53] Biswas SK, McClure D, Jimenez LA, Megson IL, Rahman I:
Curcumin induces glutathione biosynthesis and inhibit NF-kappa B activation and interleukin-8 release in alveolar epithelial cells. Mechanism of free radical scavenging activity. Anti Red Sign 2005;7: 32-41

[54] Tavafi $\mathrm{M}$ and Ahmadvand $\mathrm{H}$ : Effect of rosmarinic acid on inhibition of gentamicin induced nephrotoxicity in rats. Tissue and Cell 2011;43(6): 392-397

[55] Moreno S, Scheyer T, Romano CS, Vojnov AA: Antioxidant and antimicrobial activities of rosemary extract linked to their polyphenol composition. Free Radical Research 2006;40(2): 223-231

[56] Abdelkader MA, El-Sammad NM and Taha H: The protective role of rosemary (Rosmarinus Officinalis) in lead acetate induced toxicity in rats. J Appl Sci Res 2012;8(6): 3071-3082

[57] Osman IH and Tantaway AA: Antioxidant activity and protective effects of commercial propolis on gentamicin induced nephrotoxicity in rabbits- in vitro study. Turk $\mathrm{J}$ Biochem 2013; 38(4): 409-415

[58] Atta AH, Nasr SM, Mouneir SM, Abdel-Aziem SH and Nassar SA: Egyptian propolis alleviates gentamicin-induced nephrotoxicity in rats. J Advan Chem 2014;6(3): 1109-1119

[59] Park EH and Kahng JH: Suppressive effects of propolis in rats adjuvant arthritis. Arch Pharm Res 1999; 22: 554-8

[60] Moghaddam AH, Javaheiri M, Nabavi SF, Mohdavi MR, Nabavi SM and Ebrahimzadeh MA: Protective role of pleurotus porrigens (Angel $\square \mathrm{s}$ wings) against gentamicin-induced nephrotoxicity in mice. Eur Rev For Med Pharmacol Sci 2010;14: 1011-1014

[61] Soliman KM, Abdul-hamid M and Othman AI: Effect of carnosine on gentamicin induced nephrotoxicity. Med Sci Monit 2007;13: 73-83

[62] Sivachandran M and Hariharan P: Renoprotective effect of terminalia chebula on gentamicin induced toxicity in rats. Int J Vet Sci 2012;1(2): 76-79

[63] Salem TA, Bassiouny K, Kabel M, Elsayed IH and El-Kenaway AE: The protective role of propolis on gentamicin induced nephrotoxicity in rats. Sci J Fac Sci 2010; XXIV: $1-13$

[64] Sun F, Hayami S, Haruna S, Ogiri Y, Tanaka K and Yamada Y: In vivo antioxidative activity of propolis evaluated by the interaction with vitamin Cand $\mathrm{E}$ and the level of lipid hydroperoxides in rats. J Agricult Food Chem 2000;48(5): $1462-1465$ 